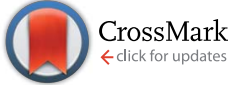

Cite this: RSC Adv., 2015, 5, 90667

Received 30th July 2015

Accepted 16th October 2015

DOI: $10.1039 / c 5 r a 15184 h$

www.rsc.org/advances

\section{Dye-sensitized-solar-cells based on calix[4]arene scaffolds $\dagger$}

\author{
M. Castillo-Vallés, ${ }^{a}$ J. M. Andrés-Castán, ${ }^{a}$ J. Garín, ${ }^{a}$ J. Orduna, ${ }^{a}$ B. Villacampa, \\ S. Franco ${ }^{\star a}$ and M. J. Blesa*a
}

We report two novel systems based on calix[4]arene scaffolds with one or two D- $\pi-A$ dyes for DSSCs which present good optical and photovoltaic properties as well as suitable electron lifetimes. The system (Cx-2-TPA) opens up the possibility to prepare more $D-\pi-A$ branched dyes for increased light-current conversion efficiencies.

During the last two decades, a great variety of donor- $\pi$-spaceracceptor $(\mathrm{D}-\pi-\mathrm{A})^{\mathbf{1}}$ dye sensitized solar cells have been prepared. This molecular structure (D- $\pi-\mathrm{A})$ leads to effective photoinduced intramolecular charge transfer from the donor to the acceptor unit to favour the electron transfer between the dye and the semiconductor $\mathrm{TiO}_{2}$. These organic systems are characterized by their high molar extinction coefficient and the lack of metal in their structure. However, one disadvantage of organic sensitizers in DSSCs is the aggregate formation, which leads to instability, and reduces electron injection. ${ }^{2}$ Aggregation can be solved by both the use of different co-adsorbents ${ }^{3}$ and the introduction of different structures, ${ }^{4}$ which decreases charge recombination processes, and improves stability. Moreover, the light-harvesting ability of the sensitizers is important for the conversion efficiency from solar light to electricity. Organic dyes with two D- $\pi$-A units have enhanced the efficiency $(\eta)$ values of DSSC solar cells compared to the corresponding single D- $\pi-\mathrm{A}$ sensitizers. ${ }^{5}$ Moreover, several anchoring groups in one molecule improve the photovoltaic properties and, at the same time, increase the stability of the dyes adsorbed on the $\mathrm{TiO}_{2}$ film. Therefore, to solve these problems, we design a new series of dyes based on calixarene scaffold to be used as DSSC sensitizers because the calix[4]arene is a versatile scaffold which can be readily functionalized. ${ }^{6}$ They have been widely investigated in different applications ${ }^{7}$ but, to the best of our knowledge, no previous research reported organic dyes based on calix[4]arene as scaffold to link chromophores for DSSC applications.

${ }^{a}$ Departamento de Química Orgánica-ICMA, Universidad de Zaragoza-CSIC, 50009-Zaragoza, Spain. E-mail: mjblesa@unizar.es; Fax: +34 976761194

${ }^{b}$ Departamento de Física de la Materia Condensada-ICMA, Universidad de ZaragozaCSIC, 50009-Zaragoza, Spain

$\dagger$ Electronic supplementary information (ESI) available. See DOI: $10.1039 / \mathrm{c} 5 \mathrm{ra} 15184 \mathrm{~h}$
The calix[4]arene structure has been used to pre-organize several chromophores in one single molecule ${ }^{8}$ in non-linear applications and the introduction of several light-harvesting units per molecule favors high molar extinction coefficients ${ }^{9}$ and allows to have several anchoring groups to improve the photovoltaic properties. The $p$-tert-butyl substituted calix[4]arene derivative has bulky alkyl chains, which increase the solubility of the systems and it is expected to impede dye aggregation. In addition, these systems can be immobilized in cone conformation by the introducing of propyl or longer groups into the lower rim. ${ }^{10}$ Despite the fact that calix[4]arene derivatives possess so many applications, the investigation of calix[4] arene-based sensitizers as a key component in DSSCs has been scarcely reported, just one paper is published with calix[4]arene as donor unit, ${ }^{11}$ not as scaffold to orient the anchoring groups. We therefore prepared for the first time systems for DSSC consisting of a tert-butyl-substituted calix[4]arene used as scaffold, a triphenylamine, one of the most common donor groups, ${ }^{\mathbf{1 2}}$ a 2 -cyanoacrylic acid acceptor, ${ }^{13}$ and a thiophene ${ }^{14}$ spacer.

The structures of dyes (TPA), (Cx-1-TPA) and (Cx-2-TPA) are depicted in Scheme 1. (TPA) is a well-known dye used for DSSC as a control in order to compare the photovoltaic properties and

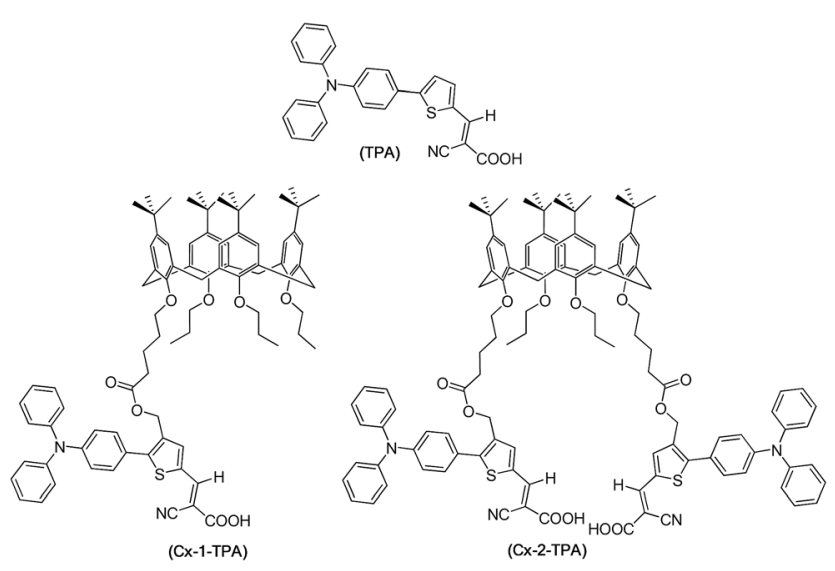

Scheme 1 


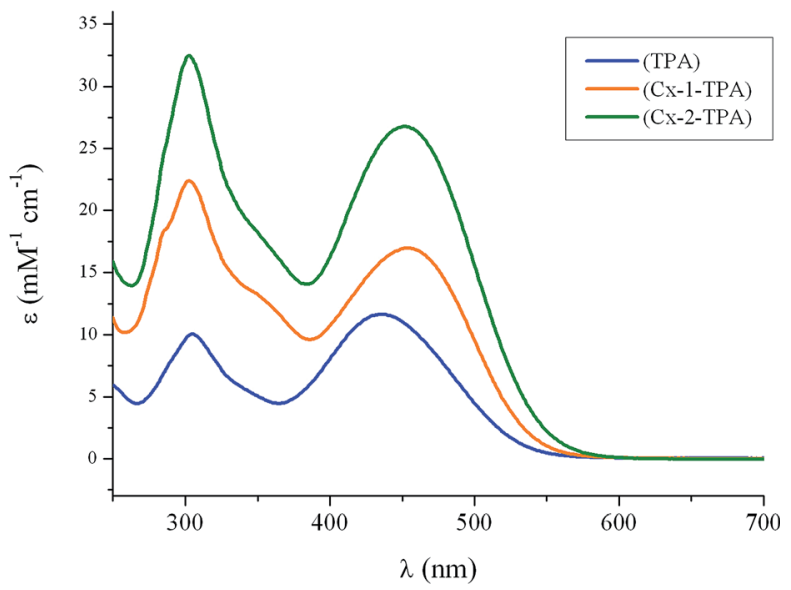

Fig. 1 Absorption spectra of solutions in $\mathrm{CH}_{2} \mathrm{Cl}_{2}$ of dyes (TPA), (Cx-1TPA) and (Cx-2-TPA).

it has been prepared following the method described in the literature. ${ }^{14 c}$ (Cx-1-TPA) and (Cx-2-TPA) dyes are synthesized according with the detailed synthesis reported in the ESI. $\dagger$

The optical properties were studied by UV-vis spectroscopy with dye solutions $10^{-5} \mathrm{M}$ in $\mathrm{CH}_{2} \mathrm{Cl}_{2}$. The absorption spectra of the dyes (TPA), (Cx-1-TPA) and (Cx-2-TPA) are shown in Fig. 1. Inspection of spectra reveals that these compounds show a band at $300 \mathrm{~nm}$ attributed to a $\pi-\pi^{*}$ transition of the conjugated molecules and also a broad absorption band in the visible region from $370 \mathrm{~nm}$ to $550 \mathrm{~nm}$, which is attributed to a strong intramolecular charge transfer transition between donor and acceptor. These studies have also established the molar extinction coefficient of these compounds. The molar extinction coefficient value is directly related to the amount of radiation that is absorbed by the molecule at a given wavelength. Table 1 shows that these dyes have molar extinction coefficients ranging from 10832 to $28136 \mathrm{M}^{-1} \mathrm{~cm}^{-1}$ and it is noticeable the increase of the value of the (Cx-2-TPA) system with respect to (Cx-1-TPA) and (TPA). This result implies that calixarene derivatives with two chromophores in the same scaffold could have potential application in lowluminosity conditions.

When dyes are attached to $\mathrm{TiO}_{2}$ surface, the maximum absorption peaks are blue shifted as compared to those in solution (Fig. S5. ESI $†$ ). In general, the blue shifts of the absorption spectra on $\mathrm{TiO}_{2}$ could be ascribed to deprotonation and/or formation of $\mathrm{H}$-aggregates (extended head to tail stacking) ${ }^{15}$ of the dyes on the $\mathrm{TiO}_{2}$ surface. The UV-vis spectra of the dyes at different times of adsorption show that the aggregation is retarded in devices prepared with (Cx-2-TPA) with respect to the ones prepared with (TPA) dye (Fig. S6 and S7 ESI† †े).

Moreover, the transition energy, $E_{0-0}$, is estimated from the intersection between the absorption and emission spectra (Fig. S8-S10 ESI†).

The electrochemical properties of the dyes (TPA) (Cx-1-TPA) and (Cx-2-TPA) were studied by Differential Pulse Voltammetry (DPV). Voltammograms were performed under argon, in $\mathrm{CH}_{2} \mathrm{Cl}_{2}$ using $0.1 \mathrm{M}$ tetrabutylammonium hexafluorophosphate as supporting electrolyte, a glassy carbon as working electrode, a Pt as counter electrode and a $\mathrm{Ag} / \mathrm{AgCl}$ as reference electrode. The solution of the dyes was $10^{-4} \mathrm{M}$ in $\mathrm{CH}_{2} \mathrm{Cl}_{2}$. The electrochemical data of these dyes are also listed in Table 1 which shows the potential oxidation of both ground and excited states of these dyes. The potential oxidation of the ground state, $E_{\text {ox }}$, is below the electrolyte potential (the redox potential $\mathrm{I}^{-} / \mathrm{I}_{3}{ }^{-}$has a value of $+0.4 \mathrm{~V}$ ), which is necessary to ensure that neutral dye is effectively regenerated after being oxidized ${ }^{16}$ and the potential oxidation of the excited state, $E_{\mathrm{ox}}^{*}$, is above the $\mathrm{TiO}_{2}$ potential in favour of efficient electron injection from the excited dye onto the $\mathrm{TiO}_{2}$ electrode. ${ }^{17}$ The potential oxidation values of dyes (TPA), (Cx-1-TPA) and (Cx-2-TPA) are very similar, $+1.17 \mathrm{~V},+1.21 \mathrm{~V},+1.24 \mathrm{~V}$, respectively and they have adequate potentials to be used as dyes for DSSCs.

Dyes (TPA), (Cx-1-TPA) and (Cx-2-TPA) were applied in DSSC as photosensitizers. In order to analyse if the use of additives can reduce the recombination process increasing the $V_{\mathrm{oc}}$ values, devices were prepared with and without a co-adsorbate (chenodeoxycholic acid, $0.3 \mathrm{mM}$ CDCA). Electrodes were dipped in dye solutions $10^{-4} \mathrm{M}$ in order to produce the adsorption of the dye. The incident photo-to-current conversion efficiencies
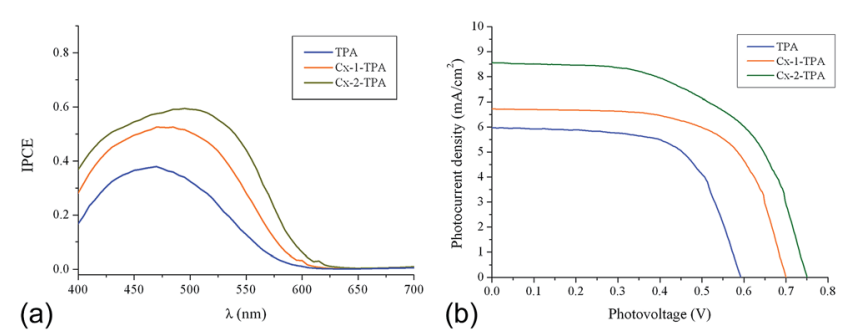

Fig. 2 (a) IPCE spectra, and (b) photocurrent density vs. photovoltage plots for DSSCs based on studied dyes under AM $1.5 \mathrm{G}$ simulated solar light $\left(100 \mathrm{~mW} \mathrm{~cm}^{-2}\right)$.

Table 1 Linear optical and electrochemical properties of dyes (TPA), (Cx-1-TPA) and (Cx-2-TPA)

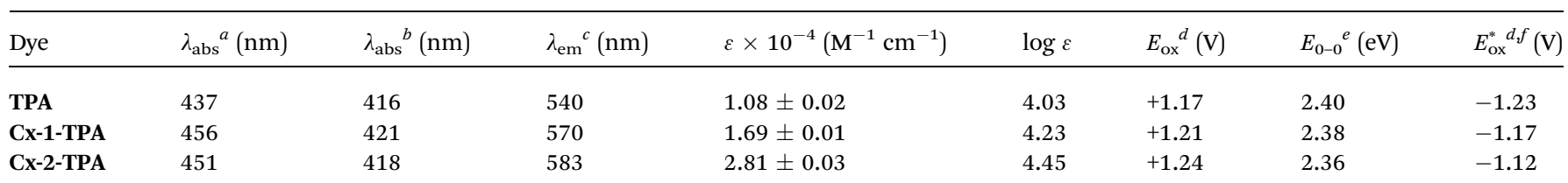

${ }^{a}$ Absorption in $\mathrm{CH}_{2} \mathrm{Cl}_{2}$ solution. ${ }^{b}$ Absorption on $\mathrm{TiO}_{2}$ films. ${ }^{c}$ Emission in $\mathrm{CH}_{2} \mathrm{Cl}_{2}$ solution. ${ }^{d}$ The oxidation potentials were converted to normal electrode (NHE) by addition of $0.199 \mathrm{~V} .{ }^{e} E_{0-0}$ was estimated from the intersection between the absorption and emission spectra. ${ }^{f}$ The estimated oxidation potential of excited state of the dye was calculated from $E_{\mathrm{ox}}{ }^{*}=E_{\mathrm{ox}}-E_{0-0}$. 
Table 2 Photovoltaic performance parameters of DSSC based on adsorbed dyes in the presence or absence of co-adsorbate (CDCA) under AM $1.5 \mathrm{G}$ simulated solar light $\left(100 \mathrm{~mW} \mathrm{~cm}^{-2}\right)$

\begin{tabular}{llllll}
\hline Dye & Additive & Amount $\left(\mathrm{mol} \mathrm{cm}^{-2}\right)$ & $V_{\text {oc }}(\mathrm{mV})$ & $J_{\text {sc }}\left(\mathrm{mA} \mathrm{cm}^{-2}\right)$ & ff $(\%)$ \\
\hline TPA & - & $5.04 \times 10^{-7}$ & 590 & 5.97 & 64.39 \\
Cx-1-TPA & - & $4.88 \times 10^{-7}$ & 705 & 6.88 & 2.27 \\
Cx-1-TPA & CDCA & $1.10 \times 10^{-7}$ & 743 & 6.14 & 3.15 \\
Cx-2-TPA & - & $2.11 \times 10^{-7}$ & 746 & 8.96 & 3.09 \\
Cx-2-TPA & CDCA & $1.38 \times 10^{-7}$ & 732 & 7.82 & 56.73 \\
\end{tabular}

(IPCEs) and the current-voltage $(J-V)$ curves for the DSSCs are plotted in Fig. 2 as measured at $100 \mathrm{~mW} \mathrm{~cm}^{-2}$ AM $1.5 \mathrm{G}$.

Table 2 lists the related performance parameters of the DSSCs, the open circuit voltage $\left(V_{\text {oc }}\right)$, the short circuit current $\left(J_{\text {sc }}\right)$, the fill factor (ff) and the overall efficiency $(\eta)$ and also de amount of adsorbed dye

The short circuit current $\left(J_{\mathrm{sc}}\right)$ and the overall yield $(\eta)$ lie in the order $(\mathbf{C x}-\mathbf{2}-\mathbf{T P A})>(\mathbf{C x}-\mathbf{1 - T P A})>($ TPA $)$ which is consistent with IPCE data. The number of light-harvesting units adsorbed onto $\mathrm{TiO}_{2}$ determines the conversion efficiency $(\eta)$. The cells based on dyes (Cx-1-TPA) and (Cx-2-TPA) work better without coadsorbate. The overall efficiency $(\eta)$ is lower with co-adsorbate due to the competition of dye and co-adsorbate for the active sites of $\mathrm{TiO}_{2}{ }^{4 b}$ Therefore, the amount of adsorbed dye is lower in the device prepared with co-adsorbate which produces the decrease of the $J_{\mathrm{sc}}$ values. Moreover, as the tendency to aggregate of the calixarene derivative (Cx-2-TPA) is lower than the sole (TPA) dye, a high $V_{\text {oc }}$ value of the cells prepared with this calixarene derivative (Cx-2-TPA) which might contribute to suppressing the electron transfer from $\mathrm{TiO}_{2}$ to the electrolyte or the oxidized dye. In order to confirm this idea, impedance studies show below the recombination resistance of calixarene derivatives.

Electrochemical impedance spectroscopy (EIS) was carried out to study the electron transport kinetics in the DSSC. The EIS spectra were performed under forward bias $(-0.65 \mathrm{~V})$ in the dark. For the frequency range investigated $(0.1 \mathrm{~Hz}$ to $100 \mathrm{kHz})$, the larger

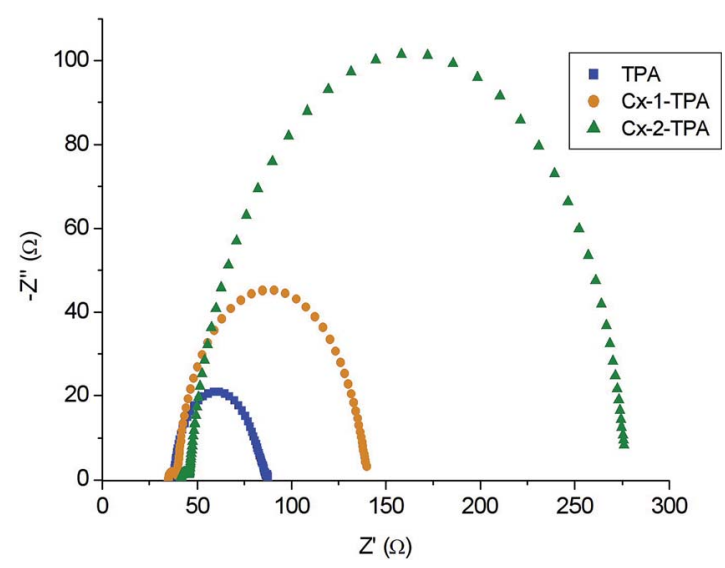

Fig. 3 Nyquist plot of devices prepared with the dyes of (TPA), (Cx-1TPA) and (Cx-2-TPA). semicircle in the Nyquist plot (Fig. 3) is related to the charge transfer resistance at the $\mathrm{TiO}_{2} /$ dye/electrolyte interface.

The differences in larger semicircles are significant, indicating that the electron recombination resistance increases from (TPA) to (Cx-1-TPA) and (Cx-2-TPA). Moreover, the electron lifetimes $\left(\tau_{\mathrm{n}}\right)$ obtained from the Bode phase plot (It can be obtained by means of equation ${ }^{\mathbf{1 8}} \tau_{\mathrm{n}}=1 / 2 \pi f_{\mathrm{p}}$ ) are $9.9 \mathrm{~ms}, 18.4 \mathrm{~ms}$ and $38.6 \mathrm{~ms}$ for (TPA), (Cx-1-TPA) and (Cx-2-TPA), respectively, which is in agreement with the higher $V_{\text {oc }}$ observed for the (Cx-2-TPA). The electron lifetime has improved in cone-calix[4] arene scaffold with two dyes.

Preliminary studies of the thermal (after $250 \mathrm{~h}$ ) and temporal (after $700 \mathrm{~h}$ ) stability of the devices prepared with the dye (Cx-2-TPA) have been carried out and the overall efficiency $(\eta)$ and the $V_{\text {oc }}$ values of these devices remains, respectively, $97 \%$ and $98 \%$ of their initial values.

In summary, it is the first time that systems based on the calix[4]arene, used as a platform, have been used in DSSC and have been linked to one or two TPA-based dyes. The device prepared with these dyes has advantages such as the slower aggregation of (Cx-2-TPA) than (TPA) dye; the noteworthy values of open circuit voltage $\left(V_{\mathrm{oc}}\right)$ and the increase on the short circuit current $\left(J_{\mathrm{sc}}\right)$. In difunctionalized calixarene systems the molar extinction coefficient has considerably increased. The (Cx-2TPA) dye has better both light-harvesting ability and electron lifetimes than (Cx-1-TPA) and (TPA) dye. And finally, these new systems could lead to the achievement of a panchromatic dye, with a large variety of novel structures with more efficient dyes.

\section{Acknowledgements}

We gratefully acknowledge the financial support from the Spanish Ministry of Science and Innovation, MICINN-FEDER (Projects CTQ2011-22727, MAT 2011-27978 and CTQ 201452331-R) and the Gobierno de Aragón-Fondo Social Europeo (E39). We also acknowledge Gemma Cepriá from Departamento de Química Analítica (Univ. Zaragoza) for the Impedance Spectroscopy support.

\section{Notes and references}

1 A. Mishra, M. K. R. Ficher and P. Bauerle, Angew. Chem., Int. Ed., 2009, 48, 2474.

2 (a) Z. Ning, Y. Fu and H. Tian, Energy Environ. Sci., 2010, 3, 1170; (b) M. Cheng, X. Yang, J. Li, F. Zhang and L. Sun, 
ChemSusChem, 2013, 6, 70; (c) Y. Hua, S. Chang, D. Huang, X. Zhou, X. Zhu, J. Zhao, T. Chen, W.-Y. Wong and W.-K. Wong, Chem. Mater., 2013, 25, 2146.

3 Z. Q. Wan, C. Y. Jia, Y. Wang and X. Y. Yao, $R S C A d v$., 2015, 5, 50813.

4 (a) Z. Ning, Q. Zhang, W. Wu, H. Pei, B. Liu and H. Tian, J. Org. Chem., 2008, 73, 3791; (b) J. Tang, J. Hua, W. Wu, J. Li, Z. Jin, Y. Long and H. Tian, Energy Environ. Sci., 2010, 3, 1736; (c) Z. Ning, Q. Zhang, H. Pei, J. Luan, C. Lu, Y. Cui and H. Tian, J. Phys. Chem. C, 2009, 113, 10307.

5 (a) Z. Wan, C. Jia, Y. Duan, X. Chen, Z. Li and Y. Lin, RSC $A d v .$, 2014, 4, 34896; (b) W.-I. Hung, Y.-Y. Liao, T.-H. Lee, Y.-C. Ting, J.-S. Ni, W.-S. Kao, J. T. Lin, T.-C. Wei and Y.-S. Yen, Chem. Commun., 2015, 51, 2152; (c) X. Ren, S. Jiang, M. Cha, G. Zhou and Z.-S. Wang, Chem. Mater., 2012, 24, 3493; (d) R. Sirohia, D. H. Kim, S. C. Yu and S. H. Lee, Dyes Pigm., 2012, 92, 1132; (e) Q. Li, J. Shi, H. Li, S. Li, C. Zhong, F. Guo, M. Peng, J. Hua, J. Qina and Z. Li, J. Mater. Chem., 2012, 22, 6689; (f) A. Abbotto, N. Manfredi, C. Marinzi, F. de Angelis, E. Mosconi, J.-H. Yum, Z. Xianxi, M. K. Nazeeruddin and M. Gratzel, Energy Environ. Sci., 2009, 2, 1094; $(g)$ S. Ramkumar and S. Ananden, RSC Adv., 2013, 3, 21535.

6 (a) P. D. Hampton, Z. Bencze, W. Tong and C. E. Daitch, J. Org. Chem., 1994, 59, 4838; (b) K. A. See, F. R. Fronczek, V. W. Watson, R. P. Kashyap and C. D. Gutsche, J. Org. Chem., 1991, 56, 7256; (c) K. Iwamoto and S. Shinkai, J. Org. Chem., 1992, 57, 7066.

7 (a) D. T. Schuhle, J. A. Peters and J. Schatz, Coord. Chem. Rev., 2011, 255, 2727; (b) J. Roymon and R. Chebsolu Pulla, Chem. Rev., 2011, 111, 4658; (c) C. M. A. Gangemi, A. Pappalardo and G. Trusso Sfrazzetto, RSC Adv., 2015, 5, 51919; (d) T. C. Gokoglan, S. Soylemez, M. Kesik, H. Unay, S. Sayin, H. B. Yildiz, A. Cirpan and L. Toppare, $R S C A d v ., 2015,5$, 35940; (e) H. Choi, J. H. Lee and J. H. Jung, RSC Adv., 2015, 5, 20066.

8 (a) P. J. A. Kenis, E. G. Kerver, B. H. M. Snellink-Ruël, G. J. van Hummel, S. Harkema, M. C. Flipse, R. H. Woudenberg, J. F. J. Engbersen and D. N. Reinhoudt, Eur. J. Org. Chem., 1998, 1089; (b) J. M. Lehn, Supramolecular Chemistry, VCH, Weinheim, 1995; (c) K. A. See, F. R. Fronczek, W. H. Watson, R. P. Kashyap and C. D. Gutsche, J. Org. Chem., 1992, 57, 7066; (d) S. H. Wong, X. L. Zhang, D. Z. Chen and W. H. Cheung, Chem. Commun., 2003, 138.

9 R. Andreu, S. Franco, J. Garín, J. Romero, B. Villacampa, M. J. Blesa and J. Orduna, ChemPhysChem, 2012, 13, 3204.

10 K. Iwamoto, K. Araki and S. Shinkai, J. Org. Chem., 1991, 56, 4955.

11 L.-L. Tan, J.-M. Liu, S.-Y. Li, L.-M. Xiao, D.-B. Kuang and C.-Y. Su, ChemSusChem, 2015, 8, 280.

12 (a) M. Liang and J. Chen, Chem. Soc. Rev., 2013, 42, 3453; (b) Z. J. Ning and H. Tiang, Chem. Commun., 2009, 5483; (c)
C. Sissa, V. Parthasarathy, D. Drouin-Kucma, M. H. V. Werts, M. Blanchard-Desce and F. Terenziani, Phys. Chem. Chem. Phys., 2010, 12, 11715; (d) J. Tang, J. Hua, W. Wu, J. Li, Z. Jin, Y. Long and H. Tian, Energy Environ. Sci., 2010, 3, 1736; (e) P. Shen, Y. Liu, X. Huang, B. Zhao, N. Xiang, J. Fei, L. Liu, X. Wang, H. Huang and S. Tan, Dyes Pigm., 2009, 83, 187.

13 (a) M. Liang, W. Xu, F. Cai, P. Chen, B. Peng, J. Chen and Z. Li, J. Phys. Chem. C, 2007, 111, 4465; (b) S. Hwang, J. H. Lee, C. Park, H. Lee, C. Kim, C. Park, M.-H. Lee, W. Lee, J. Park, K. Kim, N.-G. Park and C. Kim, Chem. Commun., 2007, 46, 4887; (c) H. Choi, C. Baik, S. O. Kang, J. Ko, M.-S. Kang, M. K. Nazeeruddin and M. Gratzel, Angew. Chem., Int. Ed., 2008, 47, 327; (d) H. Tian, X. Yang, J. Pan, R. Chen, M. Liu, Q. Zhang, A. Hagfeldt and L. Sun, Adv. Funct. Mater., 2008, 18, 3461; (e) H. Qin, S. Wenger, M. Xu, F. Gao, X. Jing, P. Wang, S. M. Zakeeruddin and G. Zakeeruddin, J. Am. Chem. Soc., 2008, 130, 9202; (f) S. Ito, H. Miura, S. Uchida, M. Takata, K. Sumioka, P. Liska, P. Comte, P. Pechy and M. Graetzel, Chem. Commun., 2008, 41, 5194; $(g)$ D. Shi, Y. Cao, N. Pootrakulchote, Z. Yi, M. Xu, S. M. Zakeeruddin, M. Graetzel and P. Wang, J. Phys. Chem. C, 2008, 112, 17478; (h) M. Xu, R. Li, N. Pootrakulchote, D. Shi, J. Guo, Z. Yi, S. M. Zakeeruddin, M. Graetzel and P. Wang, J. Phys. Chem. C, 2008, 112, 19770; (i) G. Zhang, Y. Bai, R. Li, D. Shi, S. Wenger, S. M. Zakeeruddin, M. Gratzel and P. Wang, Energy Environ. Sci., 2009, 92, 148; (j) J. T. Lin, P.-C. Chen, Y.-S. Yen, Y.-C. Hsu, H.-H. Chou and M.-C. P. Yeh, Org. Lett., 2009, 11, 97; (k) K.-F. Chen, Y.-C. Hsu, Q. Wu, M.-C. P. Yeh and S.-S. Sun, Org. Lett., 2009, 11, 377; (l) M. Xu, S. Wenger, H. Bala, D. Shi, R. Li, Y. Zhou, S. M. Zakeeruddin, M. Graetzel and P. Wang, J. Phys. Chem. C, 2009, 113, 2966.

14 (a) R. Pérez Tejada, L. Pelleja, E. Palomares, S. Franco, J. Orduna, J. Garín and R. Andreu, Org. Electron., 2014, 15, 3237; (b) X. Guo, H. N. Tsao, P. Gao, D. Xia, C. An, M. K. Nazeeruddin, M. Baumgarten, M. Graetzel and K. Mullen, RSC Adv., 2014, 4, 54130; (c) D. P. Hagberg, T. Marinado, K. M. Karlsson, K. Nonomura, P. Qin, G. Boschloo, T. Brinck, A. Hagfeldt and L. Sun, J. Org. Chem., 2007, 72, 9550; (d) S. Wang, J. Guo, L. He, H. Wang, J. Zhao and C. Lu, Synth. Met., 2013, 168, 1; (e) W. H. Liu, I.-C. Wu, C. H. Lai, P.-T. Chou, Y.-T. Li, C.-L. Chen, Y.-Y. Hsu and Y. Chi, Chem. Commun., 2008, 5152.

15 F. Nuesch and M. Gretzel, Chem. Phys., 1995, 193, 1.

16 G. Zhou, N. Pscirer, J. C. Schoneboom, F. Eickemeyer, M. Baumgarten and K. Mullen, Chem. Mater., 2008, 20, 1808. 17 P. Gao, H. N. Tsao, M. Graetzel and M. K. Nazeeruddin, Org. Lett., 2012, 14, 4330.

18 J. Bisquert, F. Fabregat-Santiago, I. Mora-Seró, G. GarcíaBelmonte and S. Giménez, J. Phys. Chem. C, 2009, 113, 17278. 